\title{
Residual gravity anomaly of Marajó basin using crustal modeling: an identification of geological features
}

\author{
Gilberto Carneiro dos Santos-Junior(PPGG/UFPA), Cristiano Mendel Martins(CPGF/UFPA) and Nelson \\ Ribeiro-Filho(PPGG/ON)
}

Copyright 2019, SBGf - Sociedade Brasileira de Geofísica

This paper was prepared for presentation during the $16^{\text {th }}$ International Congress of the Brazilian Geophysical Society, held in Rio de Janeiro, Brazil, 19 to 22 August 2019.

Contents of this paper were reviewed by the Technical Committee of the $16^{\text {th }}$ International Congress of The Brazilian Geophysical Society and do not necessarily represent any position of the SBGf, its officers or members. Electronic reproduction or storage of any part of this paper for commercial purposes without the written consent of The Brazilian Geophysical Society is prohibited.

\begin{abstract}
We use crustal modeling to obtain the residual gravimetric anomaly of Marajó basin. In this approach, the crust model was discretized in rectangular prisms, with top and bottom defined as topography and relief of the crust-mantle interface respectively, to obtain de signal calculated which was predict as regional anomaly. The simple Bouguer anomaly was used as the observed gravimetric anomaly data and subtracting the observed and the regional signals we obtained the residual gravimetric anomaly. According previous studies the result obtained proved to be efficient in the caracterization of the region.
\end{abstract}

\section{Introduction}

Gravimetric method has an application on studying sedimentary basins, which is possible due to the reason that density varies while the depth increases, along with different sediments packages. The difference between densities of sedimentary package and the basement is negative, despite the possibility of significant changes on amplitudes. Moreover, this type of displacement be falls when large-deep structures are present, especially the crust-mantle interface, usually named as Moho.

The observed gravimetric signal is a result of all possible effects (Blakely, 1996; Telford et al., 1990). Because of that, a very careful data processing is required. Furthermore, to investigate a specific signal due to a unique source, the separation of regional an residual data becomes necessary.

Regional-residual separation was studied for the past decades. Some authors analyzes the energy spectrum (Spector and Grant, 1970), while other fits a low degree polynomial (Beltrão et al., 1991), in order to calculate the residual signal. However, estimate the regional anomaly due to the Earth's crust is also an important approach for discussion (Ribeiro Filho et al., 2018).

In this work, we used the crustal modeling approach in order to obtain the residual gravimetric anomaly of Marajó basin. This basin presents a area of $\approx 162 \mathrm{~km}^{2}$, and was formed by a inter-connected graben system (Azevedo, 1991), being consequence of the aborted rift on separation between South America and Africa (Zalán and Matsuda, 2007; Soares Júnior et al., 2011). Additionally, the graben system on this basin has a high complexity, which could lead the interpreter to an erroneous interpretation

The residual anomaly is calculated by subtracting the observed gravimetric data from the predicted signal (regional), due to the surface of Moho. We use topography data from (Amante and Eakins, 2009), Moho data from (Uieda and Barbosa, 2016) and the simple Bouguer anomaly, available on ICGEM Barthelmes (2012). The results present an efficient correspondence with the geological background and seismic data (Villegas, 1994; Costa et al., 2002) as well.

\section{Methodology}

The methodology of crustal modeling consists on using a geometric model in order to evaluate the surface of Earth's crust, which normally requires an extensive processing time. Suppose that a topography model and a continentaloceanic crust could be divided by a set of rectangular prisms. To perform any type of calculation, the orientation of $x, y \mathrm{e} z$ coordinates and a choice for the quantity of prisms are necessary.

The top $z_{t}$ of each prism is set by the main topography (i.e. orthometric high), which is obtained by using the digital elevation model Etopo1 (Amante and Eakins, 2009). In the meanwhile, the bottom $z_{b}$ represent the relief of Moho, which is provided, on the other hand, by Uieda and Barbosa (2016). Once the crust is modeled and the specific number of prisms is chosen, the calculation of gravity anomaly due to the set of prisms is calculated, representing the regional anomaly $g_{\text {reg }}$ (see the Figure 1.)

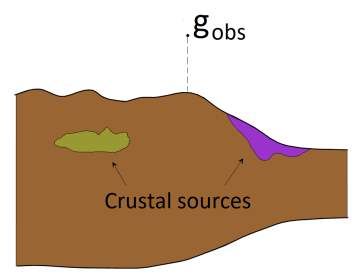

(a)

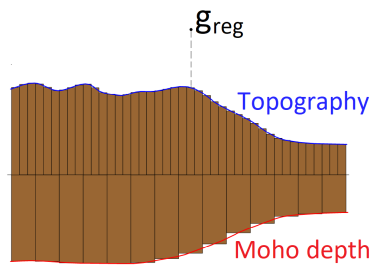

(b)
Figure 1: Ilustrative scheme of the crustal modeling. (a) Heterogeneous crust, where $g_{o b s}$ indicates the position of the gravity observation point at the surface. Homogeneous discretized crust model, where the top and bottom are the topography and the surface of Moho, specified as blue and red lines, respectively, and $g_{\text {reg }}$ represents the predicted signal (i.e. regional anomaly). 
The residual gravimetric anomaly $g_{\text {res }}$ is obtained by computing the diference between observed data $g_{o b s}$ and predicted data $g_{\text {reg }}$, written as:

$$
g_{\text {res }}=g_{\text {obs }}-g_{\text {reg }}
$$

\section{Results \& Discussion}

\section{Study area}

The Marajo basin is located in the North of Brazil (Pará state), as show in Figure 2, containing four sub-basins: Mexiana, Limoeira, Mocajuba and Cametá (Costa et al., 2002).

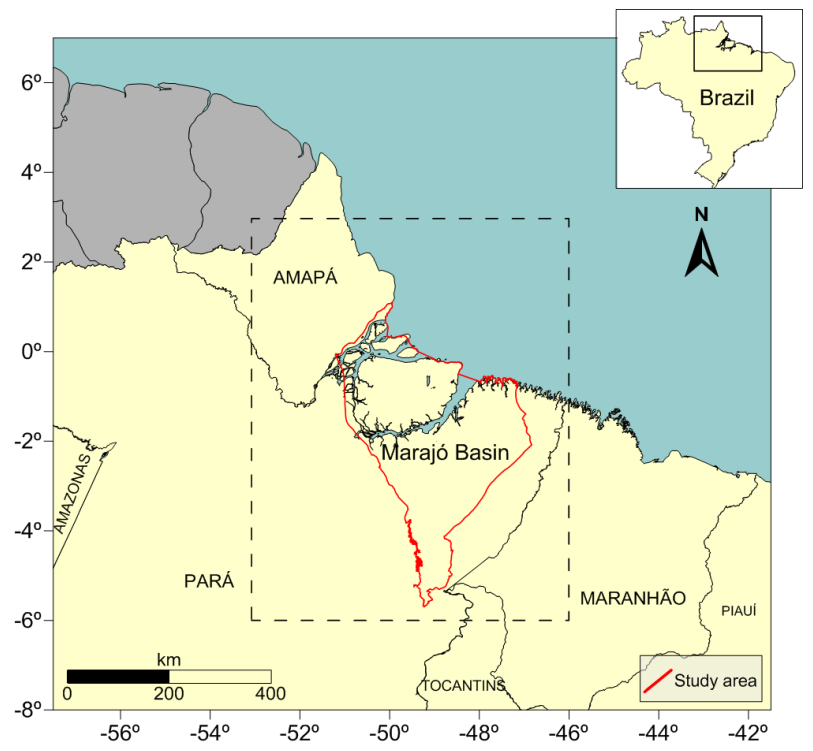

Figure 2: Location map of northern Brazil. The red line is the Marajó basin location. dashed box indicates the study area.(CPRM, 2014).

This basin was formed during the Mesozoic as well as others basins in the northern of Brazilian equatorial margin Soares Júnior et al. (2008). The presence of a large extensional rift system is associated with the opening of South Atlantic ocean. The observed gravity anomaly is presented in Figure 3, showing low negative values inside the basin and also a positive tendency in NE direction.

\section{Results}

On applying the crustal modeling, a choice for top and bottom for each prism on the voxelized surface is required. The top was set by the digital topography model Etopo1 (Amante and Eakins, 2009), while the bottom was set by the Moho surface presented in (Uieda and Barbosa, 2016). The calculation of gravimetric signal is performed and the regional anomaly is interpreted as the contribution of a high-wavelength field. By subtracting the calculated regional anomaly from the observed data, the residual signal is finally obtained. Figure 4 shows the final result by applying the regional-residual separation by means that crustal modeling, with both regional and residual anomalies of Marajó basin.

As expected, the regional anomaly presents a smooth signal, with more positive values along the ocean, following

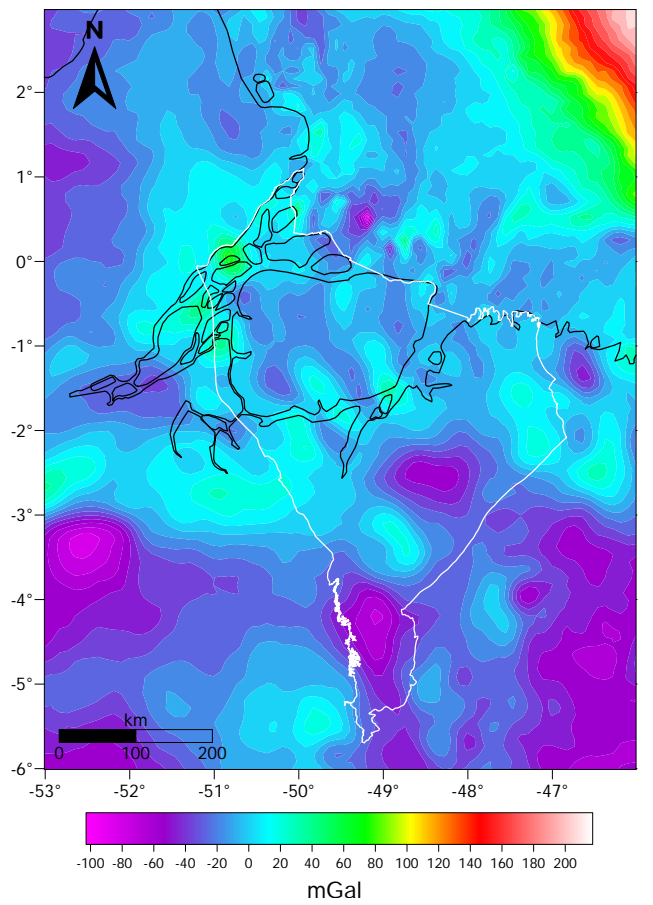

Figure 3: Observed simple Bouguer anomaly at Marajó basin. The black line represent the Brazilian coast line, while the white line indicates the basin contour.

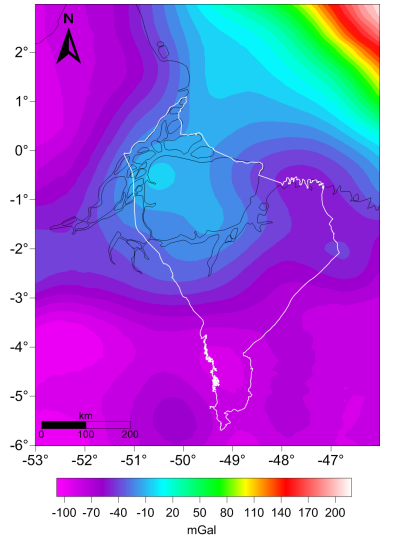

(a) Regional anomaly (mGal)

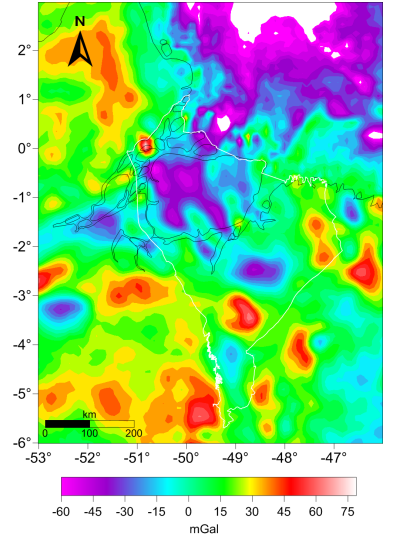

(b) Residual anomaly (mGal)
Figure 4: (a) Regional and (b) residual gravimetric anomaly of Marajó basin. The black and white lines represent the Brazilian coast line and the contour of Marajó basin, respectively.

a negative tendency in the continental part. On the other hand, the residual signal shows a zone with more negative signatures, which is significant to this study. The residual signal's behavior inside of Marajó basin could represent both shape and structure of Marajó graben system, previously sketched in Villegas (1994).

\section{Discussion}

In the Figure 5, is presented a comparation between the residual anomaly data and seismics sections. An efficiently 


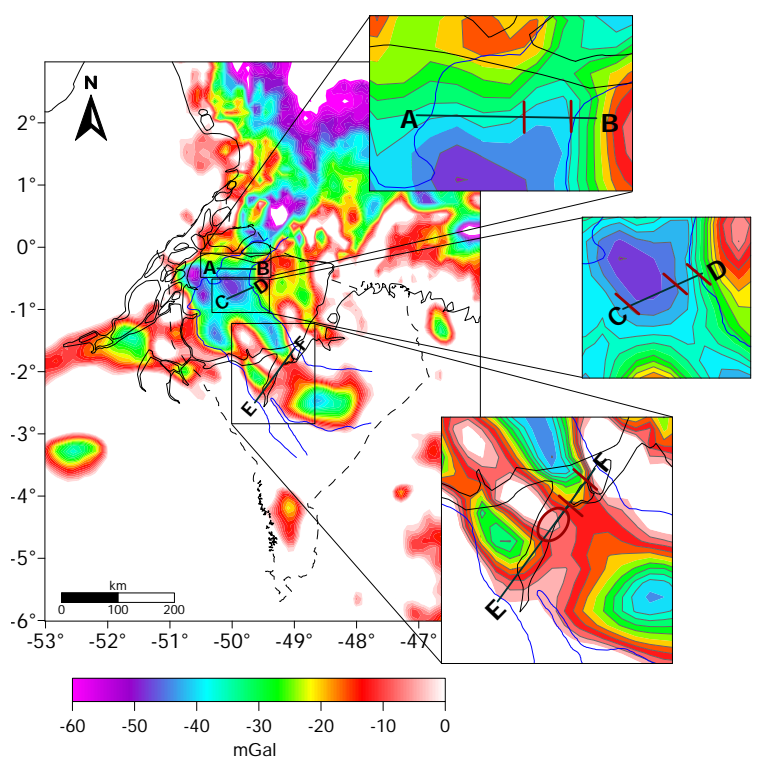

(a) Residual anomaly (mGal)
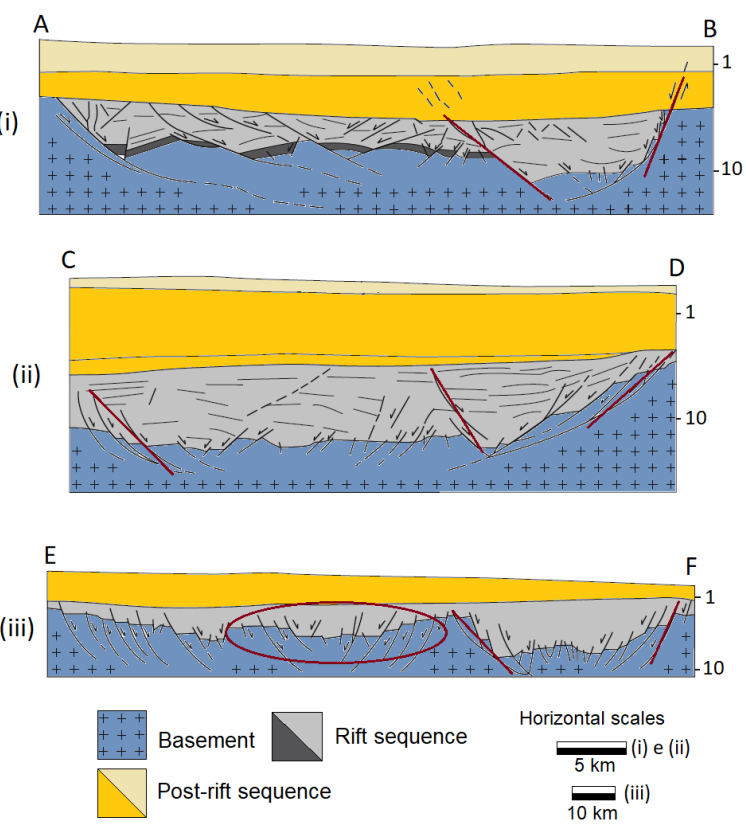

(b) Seismic profiles

Figure 5: (a) Negative residual anomaly with seismic sections illustrated in dark green line. In, black line represents the Brazilian coast line. The dashed and blue lines are the Marajó basin and the graben system, respectively. (b) Seismic sections that support gravimetric interpretation from. (I) and (II) are located in north of Limoeiro sub-basin, while (III) is more southward, nearby Mocajuba and Cametá sub-basins. The red lines and circle are the existing correlations between two data-set.(Costa et al., 2002).

identification of zero-tendencies inside Marajó basin allow the comparison between the gravimetric signature and the existing sub-basins. By considering the negative part only, an assumption that the shape of Marajó graben system and the signal are well-correlated is completely understandable. Moreover, when compared, the graben system is larger in the $N W$ direction, as well as the main part of the residual anomaly, illustrated in Figure 5-a.

Having compelling interpretation of geological structures in a sedimentary basin requires a well-comparison between two or more geophysical results. In order to confirm our hypothesis, seismic data is also used, presenting a quite good correspondence with geological features and basement structures. The seismic sections was, in essence, presented in an interesting study of (Villegas, 1994; Costa et al., 2002). Three profiles of the residual anomaly were analyzed, due to the same location of seismic data, given a possible correspondence between those data-set, as showed in Figure 5-b.

By analyzing the data, A-B presents normal faults, larger in the east part, as can be seen in seismic section; $C-D$ indicates a more specific detail, which is the presence of three main normal-reversal faults, as well as an elevation of the igneous basement in the east side, which can explain the positive values in the same profile of gravimetric data; $\mathrm{E}-\mathrm{F}$ indicates the presence of two faults, both seen in residual profile, with a positive-negative contrast. Therefore, the most interesting assumption lies on the basement elevation, centered in the seismic section, which is clearly seen in residual anomaly.

\section{Conclusions}

An special approach is presented in this work, by using crustal modeling for separating the regional and residual anomalies of gravimetric data. The crust is discretized in prisms, with geometric parameters defined by the user, while depth of top and bottom are set by the topography model and the surface of Moho. Once the crust is modeled, the residual signal is obtained by subtracting the observed data and the predicted data.

We applied this methodology at Marajó basin, where a complex graben system complicates the gravity interpretation. In order to support, seismic data are also used. Additionally, the residual anomaly clearly illustrates the Marajó graben system and the existing sub-basins, mapped in former researches. Moreover, both negative and positive sub-anomalies are related to geological faults. Therefore, the existing faults are seen as negative values in the residual data, while the main rise of basement is interpreted as a positive tendency.

\section{References}

Amante, C., and B. Eakins, 2009, Etopo1: 1 arc-minute global relief model: procedures, data sources and analysis: National Environmental Satellite, Data, and Information Service, National Geophysical Data Center Marine Geology and Geophysics Division.

Azevedo, R. P., 1991, Tectonic evolution of Brazilian equatorial continental margin basins: PhD thesis, Imperial College London (University of London).

Barthelmes, D. F., 2012, International centre for global earth models (ICGEM). 
Beltrão, J., J. Silva, and J. Costa, 1991, Robust polynomial fitting method for regional gravity estimation: Geophysics, 56, 80-89.

Blakely, R. J., 1996, Potential theory in gravity and magnetic applications: Cambridge University press, 1.

Costa, J., Y. Hasui, R. L. Bemerguy, A. V. Soares-Júnior, and J. Villegas, 2002, Tectonics and paleogeography of the Marajó basin, northern Brazil: Anais da Academia Brasileira de Ciências, 74, 519-531.

CPRM, S. G. d. B., 2014, CPRM - Geobank - download de arquivos vetoriais.

De Matos, R. M. D., 2000, Tectonic evolution of the equatorial south atlantic: Atlantic rifts and continental margins, 115, 331-354.

Ribeiro Filho, N., C. M. Martins, and R. d. S. Santos, 2018, A novel regional-residual separation approach for gravity data through crustal modeling: Revista Brasileira de Geofísica, 36, 1-15.

Soares Júnior, A. V., J. B. S. Costa, and Y. Hasui, 2008, Evolução da margem atlântica equatorial do brasil: Três fases distensivas: Geociências (São Paulo), 27, 427437.

Soares Júnior, A. V., Y. Hasui, J. B. S. Costa, and F. B. Machado, 2011, Evolução do rifteamento e paleogeografia da margem atlântica equatorial do brasil: Triássico ao holoceno: Geociências, 669-692.

Spector, A., and F. Grant, 1970, Statistical models for interpreting aeromagnetic data: Geophysics, 35, 293302.

Telford, W. M., W. Telford, L. Geldart, and R. E. Sheriff, 1990, Applied geophysics: Cambridge university press, 1.

Uieda, L., and V. C. Barbosa, 2016, Fast nonlinear gravity inversion in spherical coordinates with application to the South American Moho: Geophysical Journal International, 208, 162-176.

Villegas, J., 1994, Geologia estrutural da bacia do marajó: Belém. Dissertação de Mestrado, Centro de Geociências, Universidade Federal do Pará, Belém-PABrasil.

Zalán, P. V., and N. S. Matsuda, 2007, Bacia do Marajó: Boletim de Geociências da Petrobras, 15, 311-319. 